\title{
Pharmacovigilance: Urgent need in midwestern region of Nepal
}

Khanal S', Gyawali $S^{2}$, Kanodia $\mathbf{R}^{3}$, Rathor $\mathbf{R S}^{4}$

${ }^{1}$ Tutor, ${ }^{2}$ Lecturer, ${ }^{3}$ Undergraduate Student, ${ }^{4}$ Professor, Department of Pharmacology, Nepalgunj Medical College, Chisapani, Nepal.

$\mathrm{W}$ orld Health Organisation (WHO) defines pharmacovigilance as the 'science and activities relating to the detection, assessment, understanding and prevention of adverse effects or any other drug related problems'. With the regular increase in number of marketed drugs there is demand for the pharmacovigilance in this modern age. The concept of pharmacovigilance is relatively new in context of Nepal. Palaian et al. had nicely highlighted the importance of pharmacovigilance in context of $\mathrm{Nepal}^{2}$. With the concern on patient safety inside the hospital and to help the country on maintaining its drug safety database some of the hospitals in Nepal have already started the pharmacovigilance program. Manipal Teaching Hospital, Pokhara Nepal; Tribhuvan University Teaching Hospital, Kathmandu Nepal; Nepal Medical College, Kathmandu Nepal and KIST Medical College, Lalitpur Nepal have been recognised as regional pharmacovigilance centers by Department of Drug Administration (DDA), Nepal. A study from western region of Nepal also reports the active involvement of community pharmacists on reporting of adverse drug reactions $(\mathrm{ADRs})^{4}$.

However, the situation is very different in Midwestern region of Nepal. There is not even a single pharmacovigilance centre in this region. Neglecting one of major population will not be helpful on maintaining national database of pharmacovigilance and it will be biasness to the people living in this part of Nepal. Nepalgunj Medical College Teaching Hospital
(NGMCTH) - Kohalpur is a 700 bedded tertiary care hospital situated in Banke district and is currently providing healthcare needs to the large number of population of Midwestern and Farwestern region of Nepal. Recently Drug and Therapeutic Committee (DTC) of NGMCTH- Kohalpur had introduced ADR reporting form suggested by DDA, Nepal to the representative doctors of all clinical departments in the hospital during its meeting.

Being a person working on providing healthcare needs to people in Midwestern region and as a medical student we want to alarm all the healthcare institutions of this region and the DDA, the national drug regulatory and authority body to provide some attention toward the drug safety issues in the Midwestern region of Nepal.

\section{References}

1. Lee A, Thomas SHL. Adverse drug reaction In: Walker R, Edward C (editors). Clinical pharmacy and therapeutics. 3rd Edition. US: Churchill Livingstone; 2003.p. 33-46.

2. SubishP,Izham M, Mishra P.Pharmacovigilance: A guide for Health Care Professionals. Regional Pharmacovigilance Center 2007.

3. Subish P, Mohamed Izham MI, Mishra P, Alam K, Poudel A, Khanal S. ADR reporting by community pharmacists in Nepal. J Pharm Prac Res. 2008;38(4):331-2 